\title{
Cost implications of menstrual hygiene management in Nigeria and its associated impacts
} Authors: Esther Ejiroghene AJARI ${ }^{1,2 *}$, Temidayo Precious ABASS ${ }^{1}$, Esther Bosede Ilesanmi ${ }^{3}$, Yusuff Adebayo Adebisi ${ }^{4}$

\author{
Affiliations: \\ ${ }^{1} \mathrm{MB}$;BS, College of Medicine, University of Ibadan, Ibadan, Oyo State, Nigeria \\ ${ }^{2}$ Founder and Director, The TriHealthon, Ibadan, Oyo State, Nigeria \\ ${ }^{3}$ BSc., Faculty of Nursing, Ladoke Akintola University of Technology, Ogbomosho, Nigeria \\ ${ }^{4}$ B.Pharm, Faculty of Pharmacy, University of Ibadan, Ibadan, Oyo State, Nigeria
}

\section{Corresponding Author:}

Esther Ejiroghene Ajari ${ }^{1,2}$

Physical Address: C1, Alexander Brown Hall, University College Hospital, Ibadan, Oyo State, Nigeria

Email Address: estherejiroghene@gmail.com

Phone Number: +2347049354687

\begin{abstract}
There has been a steady rise in the recognition of Menstrual Hygiene Management (MHM) as a pressing public health issue due to several advocacy campaigns against its high cost. However, not much of such recognition has been given to it outside the non-profit sector in Nigeria. This is paradoxical considering that most menstruators in Nigeria cannot afford MHM whose cost is considered high even in developed countries. We estimated that the average lifetime cost of MHM in Nigeria is $\$ 1,120$ per menstruator and $\$ 113.57$ billion for the entire menstruating population. Although this cost is relatively lower than in other countries, Nigeria's low income level explains why there is a high prevalence of period poverty among menstruators in Nigeria. This paper discusses the intersected impacts of the cost of MHM and period poverty on the average Nigerian menstruator, his/her family, the economy, the environment and the United Nations Sustainable Development Goals. To alleviate the discussed negative effects, we suggested, as a key recommendation, the national shift from the use of disposable MHM products to that of reusable ones.
\end{abstract}

Keywords: Menstrual Hygiene Management, Menstrual pads, Menstruation, Nigeria, Period poverty, Sustainable Development Goals

\section{Background}

Menstruation is an important physiological event in the life of adolescent girls, premenopausal women, transgender men and some non-binary individuals. It involves the cyclical shedding of the endometrium, the inner uterine layer, under the control of hormones of the hypothalamopituitary axis. The resultant monthly vaginal bleeding requires adequate perineal hygiene and sanitation. Sanitary products used for menstrual hygiene management (MHM) includes absorbent materials, washing and bathing soaps, underpants, clean water etc.

Disposable menstrual pads are the most commonly used absorbent materials by menstruators in Nigeria. However, affordability is still a challenge, not only in Nigeria but globally.After menarche, there is likely to be a substantial or slight decrease in the quality of life of some menstruators, up until menopause due to various factors, a major one being the economic impact of menstruation. The state of lack of access to menstrual sanitary products, popularly known as period poverty, has numerous negative sequelae.

This paper outlines an estimation of the cost of MHM in Nigeria. It also details the impact this cost has on the average Nigerian girl/woman, her family, the Nigerian economy and the environment. Furthermore, it highlights the negative effects period poverty has on the achievement of the Sustainable Development Goals 
(SDGs).

Moreover, in this paper, for the sake of proper estimation, we will focus only on the cost of disposable menstrual pads. Furthermore, since menstruators in Nigeria are mostly cis-female, all estimations in this paper will be done using statistics related to the cis-female population.

\section{Discussion}

Most menstuators in Nigeria attain menarche at a mean age of 12.8 years and menopause at 48.4 years [2]. This implies that, on the average, he/she undergoes 427 menstrual cycles prior to menopause with each menstrual phase of the cycle lasting for a mean period of 5 days. Due to several MHM interventions, most of these menstruators have adopted the practice of changing their pads on an average frequency of 3 times per day. This translates to the usage of an estimated 6,405 disposable MHM products in the lifetime of an average menstruator in Nigeria. Noteworthy is that an average disposable pad pack costs $\$ 1.4$ and contains 8 pads. This means that the average lifetime cost of MHM in Nigeria is \$1,120 per menstruator and \$113.57 billion for the entire menstruating population, which consists of approximately 101.2 million individuals.

The World Bank's classification of Nigeria as a lower middle-income country underemphasizes the value of $\$ 1,120$ to an average menstruator. According to a 2018 report, approximately half of the country's population live on less than US\$1.90 per day [3]. The female population accounting for more than half of this statistics is not a surprise, considering that Nigeria ranked 133 out of 149 in the 2019 Global Gender Gap Indices report. Therefore, for an average menstruator, affording the cost of MHM is challenging and not without consequences.

Detailed below are the impacts of this cost on various entities and the intersections between them.

\section{Impacts on the menstruator and his/her family}

A bidirectional relationship exists between the effect of MHM cost on an average menstruator in Nigeria and on his/her family. The average fertility rate in Nigeria, as reported in 2017, is 5.5 children per female [4]. With an approximately equal female and male population in the country, it suggests that an average family will approximately consist of 4 female individuals (the mother and 3 female children). This high fertility rate compounds the effects of poverty in the country.

In actual sense, the nation's monthly minimum wage still stands at $\$ 50$ because lesser than $50 \%$ of Nigerian states has implemented payment of the new minimum wage pegged at $\$ 83.33$ [5]. This implies a probability of MHM for the family costing $16.8 \%$ of the monthly income in a family with both parents employed and engaged in financial provisions, and $33.6 \%$ in a family with a single parent or only one employed and/or contributory parent.

To cover this cost, some families cut down on the purchase of other essential needs like food, water, school supplies etc. Doing this negatively affects their daily living. Therefore, most families, instead of accepting this opportunity cost, explore unhygienic alternatives to their MHM such as the usage of tissue papers, newspapers, plantain leaves, rags etc. The resultant poor menstrual hygiene has several outcomes such as disease predisposition, education impairment, mental disorders, decrease in attainment potential (especially in the workplace) and even income reduction from missed work shifts. All these will, in turn, disrupt the income and functioning of the families of these girls/women.

\section{Impacts on the Economy}

The development of a nation's economy is intricately linked to the welfare of its citizens. Period poverty impedes the welfare of menstruators and this has led to several campaigns across Nigeria advocating that the 
government provides free supplies of MHM products to its menstruating population. This recommendation is made on the grounds that similar policies have been tested in developed countries where they contribute to economic growth. While this is a commendable endeavor, the projected development might not be immediately apparent in the case of the Nigerian economy. In fact, there might be initial negative effects on the economy before the boost.

Using Nigeria's 2019 budget of $\$ 29$ billion as an estimation reference [6], Nigeria would need four times its budget to afford the lifetime cost of MHM for its female population. Furthermore, this cost amounts to theNigeria's 2019 Nominal Gross Domestic product. Policy makers must have done this estimation and realized the unfeasibility of implementing such policy and decided to explore alternative paths to easing the burden of the MHM cost. Hence, the recent government's approval of the exemption of menstrual pads from value added taxation. Recently, value added tax was increased from 5\% to $7.5 \%$ to increase government revenue [7]. However, the exemption of essential products like menstrual pads will, invariably, decrease government revenue, which needs scaling up.

Moreover, the impairment of education, work and health resulting from the relatively high MHM cost has been shown to impede economic growth and development in any nation.

\section{Impact on the environment}

Sanitary pads are made of plastic whichsits in landfills for 500-800 years. Due to thehigh MHM cost, more menstruators, especially those in rural areas, have adapted cheaper and eco-friendly options such as menstrual cups, biodegradable pads, reusable cloth pads etc. Reusable cloth pads are becoming increasingly popular and are a sustainable sanitary option as long as they are hygienically washed and dried in sunlight. An increase in the use of reusable pads can reduce the negative impact commercial sanitary pads and their non-biodegradable materials have on the environment. They also improve waste management of MHM products.

\section{Impact on the SDGs}

The 17 SDGs are interconnected. Therefore, even if period poverty affects only one of the SDGs directly, all the goals are affected. This commentary, however, focuses on the SDGs 3, 4, 5 and 8 respectively.

\section{Good Health and Well-being (SDG 3)}

Menstruators who live below the poverty line might develop unhygienic menstrual management practices. These practices include the use of rags, toilet paper, leaves, foam piece etc. These materials are unhygienicand predisposes menstruators to diseases, especially urinary and reproductive tract infections such as bacterial vaginosis and vaginal candidiasis.

The mental health of these women arealso greatly affected, and low self-esteem is a consistent feature which can lead to anxiety and depression [10]. There is a range of persistent negative beliefs, attitudes and cultures around menstruation. These stem from a core belief that menstruation is an unclean and secret issue which should not be discussed. Due to this core belief, some women are unable to go outside, cook, use public facilities or perform certain religious rites. This situation reinforces their self-esteem drop.

\section{Quality Education (SDG 4)}

Globally, women are missing school because of their periods.In a study done in North Macedonia, it was shown that $90 \%$ of female students in rural areas miss classes for 4 to 5 days while on their period [11]. In the urban areas, the proportion reduces to $75 \%$ [11]. While data is not yet available on the period poverty prevalence in Nigeria, considering that only $21.5 \%$ of the Macedonian population lives below the poverty line [12], which is relatively low compared to Nigeria's, it can be inferred that a larger percentage of 
Nigerian women are missing a significant part of school every year, thus reducing the quality of their educationand predisposing them to school dropout.

They also miss out on sports and extracurricular activities because it is wrongly believed that girls should not be active during menstruation. This also negatively impacts the quality of their education.

In a study conducted in secondary schools in three Nigerian states, only $12 \%$ of schools had latrines of any kind [13]. In most schools, the toilets were unsegregated, inaccessible and unclean. While wastebaskets were often available, they were not usually placed in toilets, making it difficult for girls to change menstrual materials with safety, privacy and dignity. Coupled with the fear that used sanitary pads might be used for ritual purposes, most of the girls do not dispose of their pads at school and would rather stay home during their menstrual cycles [13].

\section{Gender Equality (SDG 5)}

The unhygienic practices surrounding period poverty reinforce the taboo associated with menstruation and forces women to feel ashamed about their bodies leading to low self-esteem and loss of dignity [14]. Women have also reported feelings of fear, confusion and shame during menstruation due to leakage and dropping of alternative products used, and the possibility that they would be teased or harassed by their colleagues or that they would have blood-stained clothes. Also, the long-term effects of the reduction in the quality of their education results in many women not being sufficiently economically empowered. This directly impacts some of the targets of SDG 5 such as equal rights to economic resources and empowerment of women at all levels.

\section{Decent work and economic growth (SDG 8)}

A study of women working in marketplaces in West and Central Africa revealed that theystop working during their menstrual cycle because of the lack of Water, Hygiene and Sanitation facilities [15]. There is such an inadequacy that these women have reported that they have to resort to open defecation when they are at work [15]. This situation, therefore, makes being at work during their menstrual cycles out of the question for most of them. The lack of facilities also exacerbates anxiety and stress in them and increases their vulnerability to diseases [15]. The implication of this on the economy is that women are unable to attain their full productivity potential even when they do work.

\section{Conclusion}

MHM costs and period poverty have significant impact on the menstruators in Nigeria and on the nation as a whole. This is largely due to the percentage of Nigerians living below the poverty line. Therefore, reducing poverty levels would result in an increase in disposable income so that women no longer have to forgo MHM products. It would also contribute to achieving SDGs.

Furthermore, promotion of the use of reusable and biodegradable pads should be encouraged because they are more cost-effective and environmentally sustainable. In schools, lessons on making and managing reusable padsshould be incorporated into the curriculum.

\section{Acknowledgement}

The authors would like to acknowledge members of The TriHealthon for helping with the development of this paper.

The authors received no funding for this research.

\section{Competing interests}

The authors declare no conflict of interest. 


\section{References}

1. Okonofua FE, Lawal A, Bamgbose JK. Features of menopause and menopausal age in Nigerian women. Int J Gynecol Obstet. 1990. 1;31(4):341-5. DOI: 10.1016/0020-7292(90)90912-5

2. Adebayo B. Nigeria overtakes India in extreme poverty ranking - CNN. World Poverty Clock. 2018 [Accessed May 15, 2020]. Available at: https://edition.cnn.com/2018/06/26/africa/nigeria-overtakesindia-extreme-poverty-intl/index.html

3. Fertility rate, total (births per woman) - Nigeria. World Bank. [Accessed May 15, 2020]. Available at: https://data.worldbank.org/indicator/SP.DYN.TFRT.IN?locations=NG

4. Ezigbo O. 17 States Commence Payment of Minimum Wage, Says NLC. THISDAYLIVE. 2020 [Accessed May 15, 2020]. Available at: https://www.thisdaylive.com/index.php/2020/02/04/17-statescommence-payment-of-minimum-wage-says-nlc/

5. Onuah F. UPDATE 1-Nigerian president signs \$29 bln 2019 budget into law. Reuters. 2019 [Accessed May 15, 2020]. Available at: https://www.reuters.com/article/nigeria-budget/update-1-nigerianpresident-signs-29-bln-2019-budget-into-law-idUSL8N233252

6. Alake T. Nigeria to Raise VAT to 7.5\% in 2020, Ex-Minister Ahmed Says. Bloomberg. 2019 [cited May 15, 2020]. Available at: https://www.bloomberg.com/news/articles/2019-06-25/nigeria-to-raisevat-to-7-5-from-5-in-2020-ex-minister-says

7. Elsworthy E. Women who experience period poverty more likely to suffer anxiety or depression, study claims. Independent News. 2018 [Accessed Feb 01, 2020]. Available at:

https://www.independent.co.uk/news/health/period-poverty-anxiety-depression-study-women-mentalhealth-sanitary-products-a8452581.html

8. World Health Organization. Tackling the taboo of menstrual hygiene in the European Region. WHO European region. 2018 [AccessedJan 01, 2020]. Available at:

http://www.euro.who.int/en/countries/kyrgyzstan/news/news/2018/11/tackling-the-taboo-ofmenstrual-hygiene-in-the-european-region

9. Central Intelligence Agency. The World Factbook. 2015 [AccessedJan 01, 2020].Available at:https:/www.cia.gov/library/publications/the-world-factbook/fields/221.html

10. UNICEF Nigeria. An Assessment of Menstrual Hygiene Management In Secondary Schools. 2015 [AccessedJan 01, 2020].Available at: https://www.unicef.org/nigeria/media/1256/file/Assessmentmenstrual-hygiene-management-in-secondary-schools-2.jpg.pdf

11. Tull K. Period poverty impact on the economic empowerment of women. K4D HelpDesk Service. 2019 [AccessedJan 01, 2020].Available at: https://assets.publishing.service.gov.uk/media/5c6e87b8ed915d4a32cf063a/period.pdf

12. Rockaya A. Poor Access to WASH: A barrier for women in the workplace. Social Protection Human Rights. 2016 [AccessedJan 01, 2020].Available at: https://socialprotectionhumanrights.org/expertcom/poor-access-wash-barrier-women-workplace/ 